\title{
AVALIAÇÃO QUÍMICA DE SUBSTRATOS ORGÂNICOS ARMAZENADOS E SUA EFICIÊNCIA NA PRODUÇÃO DE MUDAS DE ALFACE
}

\author{
${ }^{1}$ Luiz Fernando de Sousa Antunes; ${ }^{2}$ Dione Galvão da Silva; ${ }^{3}$ Maria Elizabeth Fernandes Correia; ${ }^{4}$ \\ Marco Antonio de Almeida Leal
}

\begin{abstract}
${ }^{1}$ Biólogo e Engenheiro Agrônomo, Mestre em Agronomia - Ciência do Solo (UFRRJ), Doutorando do Programa de Pósgraduação em Fitotecnia pela Universidade Federal Rural do Rio de Janeiro (UFRRJ), e-mail: fernando.ufrrj.agro@gmail.com; ${ }^{2}$ Engenheira agrônoma (UFRRJ), Mestra em Fitotecnia (UFRRJ) e Analista da Embrapa Agrobiologia ${ }^{3}$ Bióloga (UFRJ), Doutora em Agronomia - Ciência do Solo (UFRRJ) e Pesquisadora da Embrapa Agrobiologia; ${ }^{4}$ Engenheiro Agrônomo (UFRRJ), Doutor em Agronomia - Ciência do Solo (UFRRJ) e Pesquisador da Embrapa Agrobiologia.
\end{abstract}

RESUMO: O sucesso na produção de mudas é dependente de uma série de fatores, dentre eles a escolha de um substrato de qualidade. Os objetivos deste trabalho foram avaliar as propriedades químicas dos substratos gerados pela atividade de gongolos armazenados pelo período de três meses e posteriormente a eficiência destes substratos na produção de mudas de alface. Os tratamentos avaliados foram os substratos: S1-Gongocomposto de 90 dias; S2-Gongocomposto de 125 dias; S3Gongocomposto de 180 dias e S4-SIPA, tido como controle. Os valores de $\mathrm{pH}$, condutividade elétrica, macronutrientes e frações de nitrogênio orgânico, nítrico e amoniacal dos substratos foram caracterizados antes e após o armazenamento. A semeadura da alface foi feita em bandejas de 200 células e o delineamento utilizado foi o inteiramente casualizado, com quatro repetições, sendo cada repetição constituída por oito plantas. Aos 25 dias após a semeadura avaliou-se os parâmetros de massas fresca e seca de parte aérea, massas fresca e seca de raízes, número de folhas, altura das plantas, estabilidade do torrão e vigor de muda. O armazenamento dos substratos pelo período de três meses proporcionou alterações nos valores de $\mathrm{pH}$, condutividade elétrica e teores de macronutrientes. $\mathrm{O}$ substrato S4 seguido pelo substrato S2, foram os que proporcionaram melhor desenvolvimento das mudas de alface.

Palavras-chave: Legislação brasileira, propriedades químicas, hortaliças.

\section{CHEMICAL EVALUATION OF STORED ORGANIC SUBSTRATES AND THEIR EFFICIENCY IN THE PRODUCTION OF LETTUCE SEEDLINGS}

ABSTRACT: The success in seedling production is dependent on a number of factors, including the choice of a quality substrate. The objectives of this work were to evaluate the chemical properties of the substrates generated by the activity of millipedes stored during the period of three months and afterwards the efficiency of these substrates in the production of lettuce seedlings. The evaluated treatments 
were the substrates: S1-Millicompost of 90 days; S2-Millicompost of 125 days; S3Millicompost of 180 days and S4-SIPA, had as control. The values of pH, electrical conductivity, macronutrients and organic, nitric and ammoniacal nitrogen fractions of the substrates were characterized before and after storage. The sowing of the lettuce was done in trays of 200 cells and the design was completely randomized, with four replications, each repetition consisting of eight plants. Twenty - five days after sowing, the parameters of fresh and dry shoot mass, fresh and dry mass of roots, number of leaves, height of plants, stability of the clod and seedling vigor were evaluated. Storage of the substrates over the three-month period provided changes in $\mathrm{pH}$, electrical conductivity and macronutrient contents. The substrate $\mathrm{S} 4$ followed by substrate S2, were the ones that provided better development of the lettuce seedlings.

Keywords: Brazilian legislation, chemical properties, vegetables.

\section{INTRODUÇÃO}

O substrato para produção de mudas de hortaliças, é hoje, um dos principais componentes da cadeia produtiva na olericultura, onde suas propriedades físicas, químicas e biológicas determinarão a qualidade final das mudas a serem transplantadas aos campos de produção, o que pode refletir em incrementos na produtividade final das culturas.

Há no mercado atual brasileiro uma grande diversidade de substratos, os quais variam em preço, qualidade e composição, podendo ser de base mineral, organomineral ou orgânica. Vale lembrar que qualidade dos substratos para produção de plantas no Brasil cresceu nos últimos anos, determinado pela existência de empresas de diversos tamanhos, objetivos de produção e competitividade (ABREU et al., 2012).

Sabe-se que no cultivo orgânico de hortaliças existem dificuldades, uma delas é a de produzir mudas de boa qualidade em recipientes. O volume reduzido de substrato, que varia conforme o número de células da bandeja a ser utilizada, a proibição do uso de fertilizantes químicos de alta concentração e solubilidade contida nos substratos comerciais, podem proporcionar mudas de baixa qualidade (SOUZA; RESENDE, 2006).

A utilização de materiais existentes na propriedade ou na região, de reconhecida qualidade e adequação à produção orgânica (isentos de minerais ou outras substâncias em concentrações fitotóxicas, bem como de fitopatógenos, de pragas e de sementes ou estruturas de plantas indesejáveis), representam uma 
alternativa adequada para diminuir o custo e facilitar a produção dos substratos com qualidade desejável (SEDIYAMA et al., 2014).

Existe hoje uma biotecnologia que vem sendo aplicada na produção de substratos orgânicos, a qual consiste no reaproveitamento de resíduos agrícolas existentes na propriedade agrícola combinada com a atividade de diplópodes (conhecidos como gongolos ou piolhos-de-cobra), cujo processo é denominado de gongocompostagem. Os resíduos orgânicos oriundos deste processo está sendo conhecido como gongocomposto e no Brasil foi descrito por Antunes et al. (2016), onde os autores comprovam sua eficiência no desenvolvimento de mudas de hortaliças, além de ser uma atividade ambientalmente correta, tendo em vista que anualmente se produz grandes quantidades de resíduos lignocelulósicos que nem sempre têm uma destinação adequada.

No Brasil, o Ministério da Agricultura, Pecuária e Abastecimento (MAPA) é o órgão responsável pela legislação e regulamentação de substratos para plantas. $O$ MAPA possui três Instruções Normativas referentes aos substratos, sendo que a Instrução Normativa n. 14 (MAPA, 2004) define especificações e garantias que o fabricante deve garantir no que se refere aos parâmetros de condutividade elétrica $(\mathrm{CE})$, potencial hidrogeniônico $(\mathrm{pH})$, umidade máxima, densidade e capacidade de retenção de água (CRA). Já as instruções n. 17 (MAPA, 2007) e n. 31 (MAPA, 2008) estabelecem os métodos para a análises dos substratos para plantas.

Não é uma tarefa fácil obter um substrato de qualidade e que combine características desejáveis no que se refere à nutrição, fornecimento de água (sem excessos), aeração, baixa densidade e boa adesão às raízes, de forma que ao retirar o torrão da bandeja, este se mantenha coeso sem esboroar-se. Se tratando de substratos orgânicos, isso se torna um pouco mais complicado, pois dependendo dos materiais utilizados em sua formulação, os nutrientes poderão não estar prontamente disponíveis às plantas como se apresentam nos substratos de base mineral, estando sujeitos a ciclos de imobilização e mineralização, decorrente da atividade biológica neles presente.

Como há poucas informações na área de produção e armazenamento de substratos orgânicos, este trabalho objetivou verificar se as características químicas como $\mathrm{pH}$, condutividade elétrica e os teores de macronutrientes totais dos substratos 
gerados pela atividade de gongolos foram influenciadas pelo período de armazenamento de três meses e posteriormente avaliou-se a eficiência destes gongocompostos na produção de alface em bandejas de poliestireno expandido.

\section{MATERIAL E MÉTODOS}

O experimento foi desenvolvido na Embrapa Agrobiologia, dentro do Sistema Integrado de Produção Agroecológica (SIPA - "Fazendinha Agroecológica Km 47"), localizada em Seropédica, RJ. A altitude do local é de $33,0 \mathrm{~m}$ e o clima é classificado como Aw, com chuvas concentradas no período de novembro a março, com precipitação anual média de $1213 \mathrm{~mm}$ e temperatura média anual de $24,5{ }^{\circ} \mathrm{C}$ (CRUZ, 2005).

A primeira etapa do trabalho consistiu na produção dos gongocompostos, no período de agosto de 2015 a fevereiro de 2016. O processo de gongocompostagem seguiu a metodologia descrita por Antunes et al. (2016) e os resíduos utilizados para obtenção dos gongocompostos foram Bauhinia sp. (folhas de pata-de-vaca), Paspalum notatum (aparas de grama), Musa sp. (folhas de bananeira) e aparas de papelão, com adição de dois litros de gongolos da espécie Trigoniulus corallinus. Os substratos (tratamentos) foram produzidos em diferentes tempos de gongocompostagem: S1-Gongocomposto de 90 dias; S2-Gongocomposto de 125 dias; S3-Gongocomposto de 180 dias e S4-SIPA como controle $(83 \%$ de vermicomposto $+15 \%$ de fino de carvão vegetal e $2 \%$ de torta de mamona, utilizando-se o critério volume/volume, conforme metodologia de Oliveira et al. (2011)). Com a finalidade de avaliar de forma conjunta todos os gongocompostos, estes foram mantidos congelados após sua produção até o mês de maio.

A segunda etapa se deu no período de 02 de maio a 15 de agosto (105 dias), quando os substratos foram descongelados e mantidos sob armazenamento pelo período de três meses em embalagens plásticas lacradas com cerca de dois litros, em uma sala sem nenhum controle específico, tentando aproximar a situação real de armazenamento dos estabelecimentos comerciais.

Foram retiradas amostras antes e após o armazenamento, em triplicata, para a realização das análises químicas dos substratos. As análises de $\mathrm{pH}$ foram realizadas em solução de água destilada $(5: 1 \mathrm{v} / \mathrm{v})$ e a condutividade elétrica foi 
determinada no mesmo extrato aquoso obtido para a medição do $\mathrm{pH}$, de acordo com o método descrito por MAPA (2007). Os teores de macronutrientes (N, P, K, Ca e $\mathrm{Mg}$ ) foram determinados de acordo com a metodologia descrita por Embrapa (2005).

Foi realizado também a caracterização das formas de $\mathrm{N}$ presentes nos substratos antes e depois de armazenados, utilizando vinte gramas de cada um dos substratos avaliados para determinação dos seus teores de $\mathrm{N}$, que foram extraídos com $60 \mathrm{~mL}$ de $\mathrm{K}_{2} \mathrm{SO}_{4} 2$ mols $\mathrm{L}^{-1}$ após uma hora em um agitador rotativo a $220 \mathrm{rpm}$. O sobrenadante foi filtrado e as concentrações de nitrato $\left(\mathrm{NO}_{3}{ }^{-}\right)$e amônio $\left(\mathrm{NH}_{4}{ }^{+}\right)$ foram determinadas na solução resultante por espectrometria UV. Para a determinação de $\mathrm{NO}_{3}{ }^{-}$, foram utilizados os procedimentos descritos por Miyazawa et al. (1985), mas utilizando apenas os comprimentos de onda 220 e 275 nm. A absorvância a $275 \mathrm{~nm}$ foi multiplicada por dois e depois subtraída da absorvância a $220 \mathrm{~nm}$ para determinar a absorvância de $\mathrm{NO}_{3}^{-}$, como descrito por Olsen (2008). Para a determinação de $\mathrm{NH}_{4}^{+}$, utilizou-se o procedimento de salicilato-hipoclorito (KEMPERS; ZWEERS, 1986).

A terceira etapa do trabalho compreendeu o período de 15 de agosto a 09 de setembro de 2016, quando os substratos foram utilizados para produção das mudas de alface e procedeu-se a semeadura de alface crespa cultivar Vera no dia 15 de agosto de 2016 em bandejas de poliestireno expandido de 200 células, utilizando duas sementes peletizadas por célula. O desbaste ocorreu após nove dias da semeadura, deixando apenas uma planta por célula.

Aos 25 dias após a semeadura, retirou-se ao acaso, oito mudas de alface para avaliação dos seguintes parâmetros: massa fresca da parte aérea (MFPA), massa seca da parte aérea (MSPA), massa fresca de raízes (MFR), massa seca das raízes (MSR), número de folhas verdadeiras (NF) e altura das plantas (AP), que compreende o ponto de inserção da raiz até o ápice foliar. Para a determinação da massa seca, a parte aérea e as raízes foram acondicionadas separadamente em sacos de papel e mantidas em estufa de circulação forçada de ar, a $65^{\circ} \mathrm{C}$ por 72 horas.

O vigor das mudas e estabilidade dos torrões também foram avaliados, pois são parâmetros importantes para a etapa de transplantio e sobrevivência no campo. O vigor das mudas (VM) é uma metodologia adaptada de Franzin et al. (2005), que 
classificam como nota 1: ótimo vigor, acima de 5 folhas, altura maior que $5 \mathrm{~cm}$; nota 2: vigor bom, 4 a 5 folhas, altura maior que $5 \mathrm{~cm}$ com amarelado não proeminente; nota 3: amarelecimento notório, 4 a 5 folhas, tamanho até $5 \mathrm{~cm}$, porém com deficiência nutricional bem destacada; nota 4: deficiência nutricional, problemas na altura, número de folhas reduzido. A estabilidade do torrão (ET) é uma metodologia adaptada de Gruszynski (2002), que classifica como nota 1: $50 \%$ ou mais do torrão fica retido no recipiente na retirada da muda; nota 2: 30 a 50\% do torrão fica retido no recipiente na retirada da muda; nota 3: torrão destaca-se do recipiente, porém não permanece coeso; nota 4: o torrão é destacado completamente do recipiente e mais de $90 \%$ dele permanece coeso e o vigor das mudas.

O delineamento utilizado foi inteiramente casualizado, com quatro repetições, sendo cada parcela experimental constituída por oito plantas. Para a análise dos dados foram feitas avaliações da homogeneidade das variâncias dos erros pelo Teste de Bartlett e da normalidade pelo Teste de Shapiro-Wilk. Os dados foram submetidos à análise de variância e quando significativos pelo teste $F$, aplicou-se o teste Scott-Knott $(p<0,05)$, utilizando o programa estatístico SISVAR (FERREIRA, 2011).

\section{RESULTADOS}

O armazenamento dos substratos orgânicos durante o período de três meses foi capaz de proporcionar variações nos valores de $\mathrm{pH}$, condutividade elétrica e nos teores de macronutrientes avaliados.

Os valores de $\mathrm{pH}$ apresentaram variações dentro do limite tolerado pela legislação brasileira, estando todos em conformidade. No entanto, ocorreram diferenças estatísticas significativas nos substratos $\mathrm{S} 2$ e $\mathrm{S3}$, onde o substrato $\mathrm{S} 2$ variou 0,32 pontos para menos e o substrato S3 apresentou variação de 0,31 pontos para mais (Tabela 1), baseando-se nos valores de referência obtidos no início do armazenamento.

Tabela 1. Valores de potencial hidrogeniônico $(\mathrm{pH})$ dos substratos orgânicos aferidos inicialmente e após três meses de armazenamento.

Table 1. Values of hydrogen ionic potential $(\mathrm{pH})$ of the organic substrates measured initially and after three months of storage. 


\begin{tabular}{cccc}
\hline Substratos & \multicolumn{2}{c}{$\mathbf{p H}$} & \multirow{2}{*}{ Variação permitida* } \\
\cline { 2 - 3 } & Inicial & Armazenado & \\
\hline S1- 90 dias & $8,34 \mathrm{aA}$ & $8,35 \mathrm{aA}$ & $7,84-8,84$ \\
S2 - 125 dias & $7,69 \mathrm{aB}$ & $7,37 \mathrm{bB}$ & $7,19-8,19$ \\
S3 - 180 dias & $7,46 \mathrm{bC}$ & $7,77 \mathrm{aC}$ & $6,96-7,96$ \\
S4 - SIPA & $7,00 \mathrm{aD}$ & $7,05 \mathrm{aD}$ & $6,50-7,50$ \\
\hline
\end{tabular}

CV (\%) 0,44

*Variação máxima de 0,5 pontos para mais ou para menos, conforme a Instrução Normativa no 14 (MAPA, 2004). Médias seguidas de letras distintas, minúsculas na linha e maiúsculas na coluna, diferem entre si pelos testes de F e Scott-Knott, $(p>0,05)$, respectivamente.

A condutividade elétrica de todos os substratos apresentou valores acima do estabelecido pela legislação brasileira (Tabela 2). Os valores variaram de 21,05 a 161,87 \% a mais em relação aos valores de referência obtidos no início do armazenamento, sendo que o valor mais expressivo foi registrado para o substrato S2.

Tabela 2. Valores de condutividade elétrica (CE) dos substratos orgânicos aferidos inicialmente e após três meses de armazenamento.

Table 2. Electric conductivity values (EC) of the organic substrates measured initially and after three months of storage.

\begin{tabular}{|c|c|c|c|}
\hline \multirow{2}{*}{ Substratos } & \multicolumn{2}{|c|}{$\mathrm{CE}\left(\mathrm{dS} \mathrm{m^{-1 } )}\right.$} & \multirow{2}{*}{ Variação permitida* } \\
\hline & Inicial & Armazenado & \\
\hline S1- 90 dias & $0,65 \mathrm{bD}$ & $1,01 \mathrm{aD}$ & $0,35-0,95$ \\
\hline S2 - 125 dias & $1,39 \mathrm{bC}$ & $3,64 \mathrm{aA}$ & $1,09-1,69$ \\
\hline S3 - 180 dias & $1,63 \mathrm{bB}$ & $2,95 \mathrm{aC}$ & $1,33-1,93$ \\
\hline S4 - SIPA & $2,66 \mathrm{bA}$ & $3,22 \mathrm{aB}$ & $2,36-2,96$ \\
\hline
\end{tabular}

CV (\%) 2,45

*Variação máxima de 0,3 pontos para mais ou para menos, conforme a Instrução Normativa no 14 (MAPA, 2004). Médias seguidas de letras distintas, minúsculas na linha e maiúsculas na coluna, diferem entre si pelos testes de F e Scott-Knott $(p>0,05)$, respectivamente.

Deve-se destacar que os substratos S1, S2 e S3 (todos gongocompostos) foram os que apresentaram as maiores elevações nos valores de condutividade elétrica e os teores de nitrogênio $(N)$ destes substratos aumentaram significativamente (Tabela 3). A Figura 1 mostra as formas de $\mathrm{N}$ presentes nos substratos avaliados, revelando que $o$ armazenamento promoveu redução nos níveis de $\mathrm{N}$ orgânico para os substratos $\mathrm{S} 1, \mathrm{~S} 2$ e $\mathrm{S} 3$, aumentando os níveis de $\mathrm{N}$ em formas disponíveis às plantas, quando comparados aos valores de referência no Revista Científica Rural, Bagé-RS, volume21, n2, ano 2019 Submetido 22/09/2018. Aceito 03/05/2019. Doi: https://doi.org/10.30945/rcr-v21i2.2680 
início do armazenamento. Deve-se destacar também o aumento nos teores de fósforo $(\mathrm{P})$, potássio $(\mathrm{K})$, cálcio $(\mathrm{Ca})$ e magnésio $(\mathrm{Mg})$, sendo que para os valores de $\mathrm{Mg}$ a variação foi de 45,38 a $58,83 \%$ a mais para os substratos S4 e S1, respectivamente, quando comparado com os valores de referência.

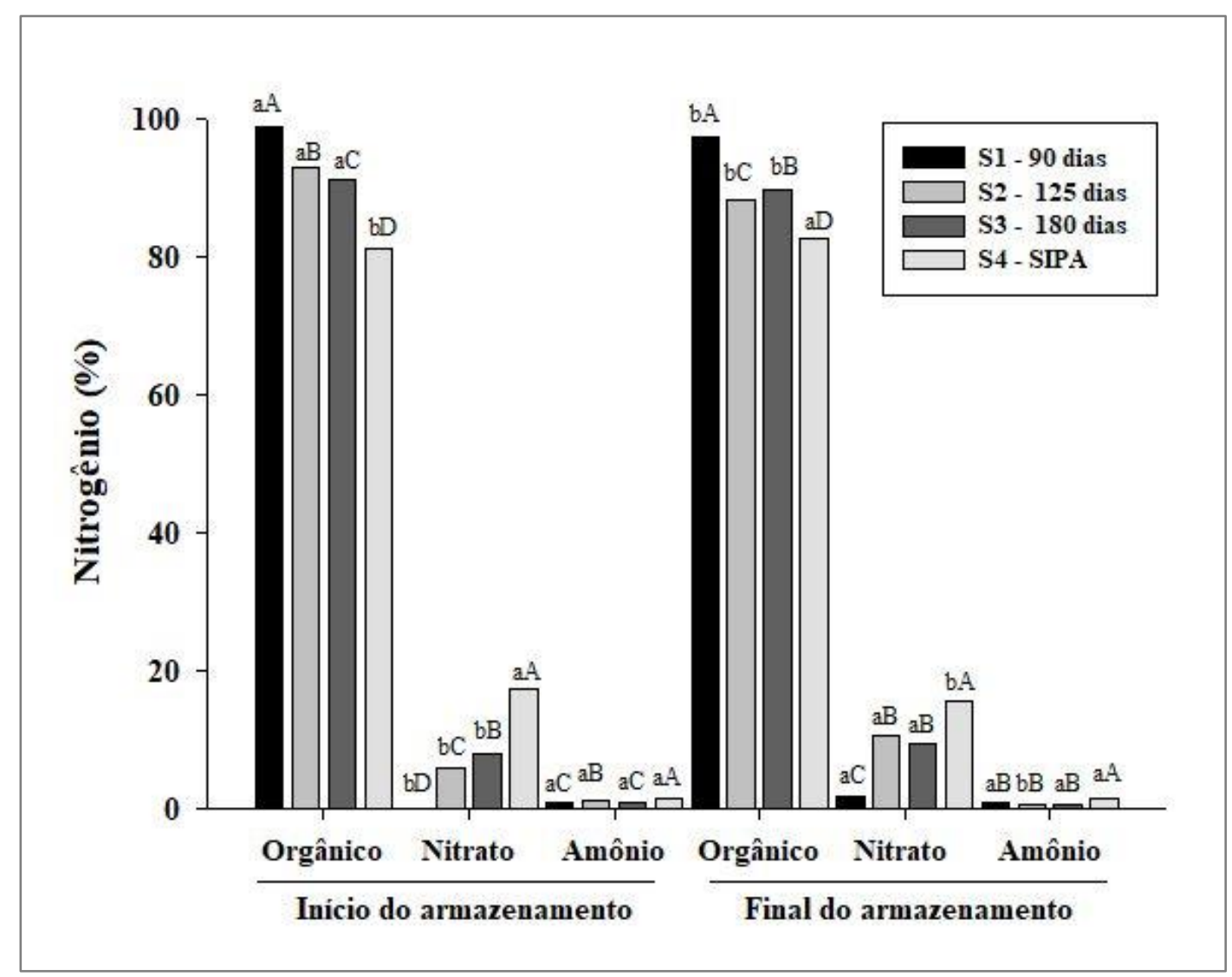

Figura 1. Formas de nitrogênio (\%) presentes nos substratos utilizados para produção de mudas de alface crespa cv. Vera no início e após três meses de armazenamento. Médias seguidas de letras distintas, minúsculas e maiúsculas nas barras, diferem entre si pelos testes de $F$ e Scott Knott, a $5 \%$ de probabilidade, respectivamente.

Figure 1. Nitrogen forms (\%) present on the substrates used for the production of crisp lettuce seedlings cv. Vera at the beginning and after three months of storage. Means followed by distinct uppercase and lowercase letters in the bars differ from the $\mathrm{F}$ and Scott Knott tests at $5 \%$ probability, respectively.

O substrato S4 (Tabela 4), diferenciou-se dos demais substratos na produção das mudas de alface quanto aos parâmetros de massa fresca e seca de parte aérea, massa fresca e seca de raízes, altura de plantas e estabilidade do torrão. 
Tabela 3. Análise química dos macronutrientes totais presentes nos substratos inicialmente e após três meses de armazenamento.

Table 3. Chemical analysis of the total macronutrients present on substrates initially and after three months of storage.

\begin{tabular}{|c|c|c|}
\hline \multirow{3}{*}{$\begin{array}{l}\text { Substratos } \\
\text { S1 - } 90 \text { dias }\end{array}$} & $N_{\text {Inicial }}$ & $\mathbf{N}_{\text {Armazenado }}$ \\
\hline & \multicolumn{2}{|c|}{$\mathrm{g} \mathrm{kg}^{-1}$} \\
\hline & $9,13 \mathrm{bC}$ & $9,86 \mathrm{aC}$ \\
\hline S2 - 125 dias & $10,99 \mathrm{bB}$ & $11,50 \mathrm{aB}$ \\
\hline S3 - 180 dias & $10,69 \mathrm{bB}$ & $11,20 \mathrm{aB}$ \\
\hline S4 - SIPA & $12,00 \mathrm{aA}$ & $12,00 \mathrm{aA}$ \\
\hline CV \% & \multicolumn{2}{|c|}{2,89} \\
\hline \multirow{2}{*}{ Substratos } & $\mathbf{P}_{\text {Inicial }}$ & P Armazenado \\
\hline & \multicolumn{2}{|c|}{$\mathrm{g} \mathrm{kg}^{-1}$} \\
\hline S1 - 90 dias & 0,62 bD & $0,75 \mathrm{aC}$ \\
\hline S2 - 125 dias & $0,80 \mathrm{bC}$ & $0,99 \mathrm{aB}$ \\
\hline S3 - 180 dias & $0,99 \mathrm{aB}$ & $1,02 \mathrm{aB}$ \\
\hline S4 - SIPA & $3,92 \mathrm{aA}$ & 3,94 aA \\
\hline CV \% & & \\
\hline \multirow{2}{*}{ Substratos } & $\mathrm{K}$ Inicial & K Armazenado \\
\hline & \multicolumn{2}{|c|}{$\mathrm{g} \mathrm{kg}^{-1}$} \\
\hline S1-90 dias & $2,97 \mathrm{bD}$ & $3,51 \mathrm{aC}$ \\
\hline S2 - 125 dias & $3,72 \mathrm{aB}$ & $3,79 \mathrm{aB}$ \\
\hline S3 - 180 dias & 3,34 bC & $3,72 \mathrm{aB}$ \\
\hline S4 - SIPA & 5,93 aA & 6,23 aA \\
\hline CV \% & & \\
\hline \multirow{2}{*}{ Substratos } & $\mathrm{Ca}$ Inicial & Ca Armazenado \\
\hline & \multicolumn{2}{|c|}{$\mathrm{g} \mathrm{kg}^{-1}$} \\
\hline S1 - 90 dias & $12,87 \mathrm{bC}$ & $15,28 \mathrm{aC}$ \\
\hline S2 - 125 dias & $16,12 \mathrm{aB}$ & $17,46 \mathrm{aB}$ \\
\hline S3 - 180 dias & $16,87 \mathrm{aA}$ & $18,62 \mathrm{aA}$ \\
\hline S4 - SIPA & $10,55 \mathrm{aD}$ & $11,02 \mathrm{aD}$ \\
\hline CV \% & & \\
\hline \multirow{2}{*}{ Substratos } & Mg Inicial & Mg Armazenado \\
\hline & \multicolumn{2}{|c|}{$\mathrm{g} \mathrm{kg}^{-1}$} \\
\hline S1 - 90 dias & $0,91 \mathrm{bB}$ & $2,21 \mathrm{aC}$ \\
\hline S2 - 125 dias & $1,15 \mathrm{bB}$ & $2,72 \mathrm{aB}$ \\
\hline S3 - 180 dias & $1,20 \mathrm{bB}$ & $2,77 \mathrm{aB}$ \\
\hline S4 - SIPA & 2,76 bA & 5,06 aA \\
\hline CV \% & & \\
\hline
\end{tabular}

Médias seguidas de letras distintas, minúsculas na linha e maiúsculas na coluna, diferem entre si pelos testes de F e Scott Knott $(p>0,05)$, respectivamente. 
A nota de vigor das mudas para os substratos S2 e S4 não diferiram estatisticamente entre si e foram significativamente melhores que as notas obtidas pelos substratos S1 e S3 (Tabela 4) e suas condutividades elétricas de 3,22 e 3,64 $\mathrm{dS} \mathrm{m}^{-1}$ foram superiores às dos demais substratos (Tabela 2). Em relação à estabilidade do torrão, apenas o substrato S4 diferiu estatisticamente dos demais, apresentado melhor coesão do torrão quando feita a retirada da muda (Tabela 4).

Tabela 4. Valores médios de massa fresca da parte aérea (MFPA), massa seca da parte aérea (MSPA), massa fresca das raízes (MFR), massa seca das raízes (MSR), número de folhas por planta (NF), altura de planta em centímetros (AP), vigor de muda (VM) e estabilidade do torrão (ET) de mudas de alface crespa cv. Vera, cultivadas em quatro diferentes substratos, aos 25 dias após semeadura.

Table 4. Average values fresh mass of shoot (MFPA), dry shoot mass (MSPA), fresh root mass (MFR), dry mass of the roots (MSR), number of leaves per plant (NF), plant height at centimeters (AP), seedling vigor (VM) and stability of the clod (ET) of crisp lettuce seedlings cv. Vera, cultivated on four different substrates, at 25 days after sowing.

\begin{tabular}{|c|c|c|c|c|c|c|c|c|}
\hline \multirow{2}{*}{ Substratos } & MFPA & MSPA & MFR & MSR & \multirow{2}{*}{ NF } & \multirow{2}{*}{ AP } & \multirow{2}{*}{ VM } & \multirow{2}{*}{ ET } \\
\hline & \multicolumn{4}{|c|}{----------------- miligramas planta"1 ----------------- } & & & & \\
\hline S1 - Gongocomposto 90 dias & $288 \mathrm{c}$ & $21 \mathrm{c}$ & $151 \mathrm{c}$ & $13 \mathrm{~b}$ & $4,97 \mathrm{a}$ & $4,35 \mathrm{c}$ & $3,00 \mathrm{~b}$ & $1,91 \mathrm{~b}$ \\
\hline S2 - Gongocomposto 125 dias & $389 \mathrm{~b}$ & $29 \mathrm{~b}$ & 298 b & $21 \mathrm{~b}$ & $5,06 \mathrm{a}$ & $4,95 \mathrm{~b}$ & $2,41 \mathrm{a}$ & $2,66 \mathrm{~b}$ \\
\hline S3 - Gongocomposto 180 dias & $189 \mathrm{~d}$ & $16 d$ & $143 c$ & $11 \mathrm{~b}$ & $4,22 b$ & $4,31 \mathrm{c}$ & $3,38 b$ & $2,25 \mathrm{~b}$ \\
\hline S4 - SIPA & $520 \mathrm{a}$ & $37 \mathrm{a}$ & $398 \mathrm{a}$ & $37 \mathrm{a}$ & $5,22 \mathrm{a}$ & $5,99 a$ & $1,88 \mathrm{a}$ & $3,75 a$ \\
\hline CV\% & 12,71 & 12,44 & 23,35 & 30,63 & 5,04 & 3,42 & 15,01 & 15,06 \\
\hline
\end{tabular}

Médias seguidas pela mesma letra na coluna não diferem pelo teste de Scott-Knott $(p<0,05)$

\section{DISCUSSÃO}

Abreu et al. (2012) ao avaliarem amostras de substratos comercializados no Brasil, sendo oito de origem orgânica e uma de origem sintética, observaram que em três amostras de substratos de origem orgânica não ocorreram desvios de $\mathrm{pH}$ maiores que os valores tolerados pela legislação brasileira, atribuindo essa pouca variação ao tipo de matéria orgânica empregada na formulação dos substratos, mais estáveis em relação aos demais substratos, corroborando assim com os resultados encontrados neste trabalho.

Os gongocompostos apresentaram valores de $\mathrm{pH}$ (Tabela 1) e Ca (Tabela 3) estatisticamente superiores em relação ao substrato $\mathrm{S} 4$. Os maiores teores de $\mathrm{Ca}$ são decorrentes da baixa sobrevivência dos gongolos durante o processo de gongocompostagem, pois seus exoesqueletos são ricos em cálcio, que acabam 
sendo mineralizados e ocasionam a liberação dos nutrientes no composto, proporcionando assim os valores de $\mathrm{pH}$ superiores nos gongocompostos.

Toledo et al. (2013) ao avaliarem o teor de nutrientes em mudas de eucalipto e a qualidade química dos substratos formados a partir de um composto orgânico oriundo de resíduos do processo de fabricação de celulose, observaram que o aumento da porcentagem do composto orgânico no substrato base elevou os valores do $\mathrm{pH}$, chegando ao valor de $\mathrm{pH} 8,0$ no substrato com $100 \%$ de composto orgânico. Barretto (2008) verificou elevação do pH no solo em decorrência do aumento da porcentagem de composto orgânico adicionado, atribuindo estes resultados pela presença de carbonatos e óxidos de cálcio na composição do composto, o que confere uma característica de corretivo de acidez.

Aumentos da condutividade elétrica em várias amostras de substratos analisados depois de armazenados também foram observados por Abreu et al. (2012), que atribuíram estas variações à decomposição dos materiais contidos nos substratos, os quais promoveram 0 aumento na concentração de sais. Provavelmente a fauna microbiana associada aos substratos tenha sido a responsável pela elevação nos valores da condutividade elétrica, haja visto que todos em todos os substratos os níveis de macronutrientes se elevaram no período em que ficaram armazenados (Tabela 3).

O aumento nos níveis de $\mathrm{N}$ durante o armazenamento dos substratos corrobora com Correia, Aquino (2005), que descreveram a existência de interações de diversos microrganismos com os gongolos, dentre elas destaca-se a ocorrência de um "rúmen externo", o qual permite a ação de microrganismos nos péletes fecais excretados por estes invertebrados, promovendo assim uma maior disponibilidade de nutrientes decorrentes do processo de mineralização, como pode ser observado na Figura 1.

A resposta das plantas a diferentes substratos está estritamente relacionada com as espécies testadas. Nem todos os substratos são considerados ideais para o crescimento das plantas em recipientes, sendo o $\mathrm{pH}$ e a salinidade fatores limitantes para seu uso, pois podem causar fitotoxicidade ou estresse salino (GARCIA-GOMEZ et al., 2002, GRIGATTI et al., 2007). 
Antunes et al. (2016) ao avaliarem o desenvolvimento das mudas de alface em gongocomposto e vermicomposto, não observaram diferenças estatísticas entre os substratos para os parâmetros avaliados. As massas frescas de parte aérea encontradas no gongocomposto e vermicomposto foram de 620 e $570 \mathrm{mg}$, respectivamente e são superiores aos valores encontrados nos gongocompostos e vermicomposto deste trabalho. De forma contrária, os valores de massa seca de parte aérea, com exceção do substrato $\mathrm{S} 3$, superam os $20 \mathrm{mg}$ encontrados pelos autores supracitados para ambos os substratos. Costa (2014) relata que a alface é uma espécie adaptada a solos alcalinos, tolerando $\mathrm{pH}$ de 6,5 a 7,5. A menor massa fresca e seca para o substrato S3 pode ter sido influenciada pelo pH de 7,77 (Tabela 1), acima do tolerável para a alface, restringindo a absorção de micronutrientes.

Diniz et al. (2006) relataram que é possível saber qual substrato forneceu maior quantidade de nutrientes para as mudas de acordo com a massa de matéria seca. As massas frescas e secas de raízes de todos os substratos proporcionaram pesos superiores (Tabela 4) aos encontrados por Antunes et al (2016), os quais registraram para a massa fresca de raízes um peso de 100 e $110 \mathrm{mg}$ para o gongocomposto e vermicomposto, respectivamente e para a massa seca de raízes os valores foram de $4 \mathrm{mg}$ para o gongocomposto e $3 \mathrm{mg}$ para o vermicomposto.

Segundo Trani et al. (2004), o transplante das mudas deve ser realizado com duas a três folhas definitivas, aproximadamente. Neste sentido, todos os substratos testados neste trabalho atendem a este requisito (Tabela 4). Diniz et at. (2006) ao avaliarem o efeito de substratos à base de húmus na produção de mudas de tomate, pimentão e alface, obtiveram o resultado de três folhas para a alface cv. Vera aos 20 dias após a semeadura, sendo inferior aos resultados obtidos neste trabalho.

Cabral et al. (2011) encontraram no substrato com $50 \%$ de esterco bovino e $50 \%$ de palhada de feijão superioridade na altura de plantas em relação ao produto comercial mais utilizado, o substrato Plantmax ${ }^{\circledR}$, que foram 4,51 e $2,87 \mathrm{~cm}$, respectivamente. Embora tenha havido diferenças estatísticas entre os substratos testados neste trabalho, os substratos S2 e S4 apresentaram altura de plantas superiores (Tabela 4) em relação ao substrato com 50\% de esterco bovino e 50\% de palhada de feijão e os substratos S1 e S3 têm suas alturas de plantas superiores ao substrato comercial Plantmax ${ }^{\circledR}$. 
Trani et al. (2007) ao avaliarem as mudas de alface desenvolvidas nos substratos Esfagno, GIII e Plantmax com condutividade elétrica de 2,1; 2,5 e 3,0 dS $\mathrm{m}^{-1}$, respectivamente, observaram que as mudas não apresentaram sintomas de crestamento de folhas provavelmente devido ao efeito tampão do material orgânico destes substratos têm influência sobre a ação dos sais que podem prejudicar a germinação e o desenvolvimento das mudas de alface. Fabri (2004) observou que mudas de alface se desenvolveram melhor nos substratos constituídos de adubo de curral e húmus, apresentando condutividade elétrica de 3,73 e 4,87 dS $\mathrm{m}^{-1}$, respectivamente.

Diante de bons resultados das mudas de alface desenvolvidas nos substratos S4 e S2 e que foram alcançados em condutividades elétricas superiores a 2,0 dS m1, que é a máxima tolerada para a alface segundo Andriollo et al., 2005), deve-se levar em consideração um outro fator além das características químicas dos substratos e que pode interferir de forma benéfica na obtenção de melhores vigores das mudas de alface e de tantas outras hortaliças, que é o fator biológico.

$\mathrm{O}$ armazenamento dos substratos durante o período de três meses pode ter sido o responsável na diminuição da atividade biológica, inativando a ação de bactérias benéficas ao crescimento de plantas. Segundo Farrar et al. (2014), os benefícios na utilização de biofertilizantes se destacam por incluir fontes baratas de nutrientes, as quais são excelentes fornecedoras de nutrientes e de matéria orgânica, promovendo ainda o crescimento às plantas, facilitando a aquisição de recursos ou ainda modificando os níveis hormonais das plantas e de forma indireta reduzindo os efeitos inibitórios de vários agentes patogénicos no crescimento e desenvolvimento das plantas (MAHANTY et al., 2016).

\section{CONCLUSÕES}

O armazenamento dos substratos no período de três meses foi capaz de alterar o $\mathrm{pH}$, a condutividade elétrica e teores de macronutrientes.

Os substratos apresentaram resultados diferentes na formação das mudas de alface, sendo que o substrato $S 4$ apresentou melhores resultados para todos os parâmetros analisados, seguido do substrato S2. Essa variação no desenvolvimento das mudas sugere que além da influência química, pode haver influência da 
atividade microbiana, que precisa ser estudada para compreender melhor sua participação no desenvolvimento vegetal.

Neste sentido, outros estudos deverão ser realizados para melhor compreender a dinâmica destes substratos orgânicos quando submetidos ao armazenamento, contando com a caracterização do microbioma presente nestes e em outros substratos, além da avaliação destes por maiores períodos de armazenamento e posteriores testes de eficiência com plantas.

\section{REFERÊNCIAS}

ABREU, M. F.; DIAS, R.S.; ABREU, C. A.; GONZALEZ, A. P. Reavaliação dos critérios constantes na legislação brasileira para análises de substratos. Bragantia, Campinas, v. 71, n. 1, p.106-111, 2012.

ANDRIOLLO, J. L.; LUZ, G. L. da; WITTER, M. H.; GODOI, R. dos S.; BARROS, G. T.; BORTOLOTTO, O. C. Growth and yield of lettuce plantsunder salinity. Horticultura Brasileira, v.23, p.931-934, 2005.

ANTUNES, L. F. S.; SCORIZA, F. N.; SILVA, D. G.; FERNANDES, M. E. C. Production and efficiency of organic compost generated by millipede activity. Ciência Rural, Santa Maria-RS, v. 46, n.5, p.815-819, 2016. DOI: http://dx.doi.org/10.1590/0103-8478cr20150714.

BARRETTO, V. C. M. Resíduos de indústria de celulose e papel na fertilidade do solo e no desenvolvimento de eucalipto. 2008. 64 f. Tese (Doutorado em Agronomia) - Universidade Estadual Paulista, Jaboticabal, 2008.

CABRAL, M. B. G; SANTOS, G. A.; SANCHEZ, S. B.; LIMA, W. L.; RODRIGUES, W. N. Avaliação de substratos alternativos para produção de mudas de alface utilizados no sul do estado do Espírito Santo. Revista Verde (Mossoró - RN - Brasil) v.5, n.1, p. $43-48,2011$.

CORREIA, M. E. F.; AQUINO, A. M. Os Diplópodes e suas associações com microrganismos na ciclagem de nutrientes / Adriana Maria de Aquino. Seropédica: EMBRAPA Agrobiologia, 2005. 41 p. (Embrapa Agrobiologia. Documentos, 199). 
COSTA, A. R. Nutrição Mineral de Plantas Vasculares. Escola de Ciências e Tecnologia da Universidade de Évora, Portugal. 2014. 147p. Disponível em: $<$ https://dspace.uevora.pt/rdpc/bitstream/10174/12007/1/NUTRI\%C3\%87\%C3\%83O \%20MINERAL\%20DAS\%20PLANTAS\%20VASCULARES.pdf> Acesso em: 06 jan. 2017.

CRUZ, F. A. DA. Instalação e calibração de lisímetro de pesagem e determinação da evapotranspiração de referência para a região de SeropédicaRJ. 2005. 65p., (Dissertação, mestrado em Fitotecnia), Universidade Federal Rural do Rio de Janeiro, Seropédica-RJ, 2005.

DINIZ, K. A; GUIMARÃES, S. T. M. R.; LUZ, J. M. Q. Húmus como substrato para a produção de mudas de tomate, pimentão e alface. Bioscience Journal, Uberlândia, v. 22 , n. 3, p. 63-70. 2006.

EMBRAPA. Manual de laboratórios: solo, água, nutrição, animal e alimentos. São Carlos: Embrapa Pecuária Sudeste, 2005. 334p.

FABRI, E. G. Determinação da qualidade dos substratos comercializados em Piracicaba - SP. Piracicaba: USP-ESALQ. (Dissertação de mestrado) 88p. 2004.

FARRAR, K.; BRYANT, D.; COPE-SELBY, N. Understanding and engineering beneficial plant-microbe interactions: plant growth promotion in energy crops. Plant Biotechnology Journal, 12(9):1193-1206, 2014. DOI: 10.1111/pbi.12279.

FERREIRA, D. F. Sisvar: a computer statistical analysis system. Ciência e Agrotecnologia (UFLA), v. $35, \quad$ n.6, p. 1039-1042, 2011. DOI: http://dx.doi.org/10.1590/S1413-70542011000600001.

FRANZIN, S. M.; MENEZES, N. L.; GARCIA, D. C.; SANTOS, O. S. Efeito da qualidade das sementes sobre a formação de mudas de alface. Horticultura Brasileira, Brasília, v.23, n.2, p.193-197, 2005.

GARCIA-GOMEZ, A.; BERNAL, M. P.; ROIG, A. Growth of ornamental plants in two composts prepared from agro-industrial wastes. Bioresource Technology, 83, 8187, 2002. DOI: https://doi.org/10.1016/S0960-8524(01)00211-5. 
GRIGATTI, M.; GIORGIONI, M. E.; CIAVATTA, C. Compost-based growing media: influence on growth and nutrient use of bedding plants. Bioresource Technology, 98, 3526-3534, 2007. DOI: 10.1016/j.biortech.2006.11.016.

GRUSZYNSKI, C. Resíduo agro-industrial "casca de tungue" como componente de substrato para plantas. 2002. p. 41. Porto Alegre: Universidade Federal do Rio Grande do Sul. Dissertação (Mestrado).

KEMPERS, A. J.; ZWEERS, A. Ammonium determination in soil extracts by the salicylate method. Communications in Soil Science and Plant Analysis,. 17, 715723, 1986.

MAHANTY, T.; BHATTACHARJEE, S.; GOSWANI, M.; BHATTACHARRYA, P.; DAS, B.; GHOSH, A.; TRIBEDI, P. Biofertilizers: a potential approach for sustainable agriculture development. Environmental Science and Pollution Research. p.1-21, 2016. DOI: https://doi.org/10.1007/s11356-016-8104-0.

MINISTÉRIO DA AGRICULTURA, PECUÁRIA E ABASTECIMENTO (MAPA). Instrução Normativa SDA N. 31 . Diário Oficial da União- Seção 1, 24 de outubro de 2008. Alteração dos subitens 3.1.2, 4.1 e 4.1.2 da Instrução Normativa n.․ 17 de 21/05/2007. Métodos Analíticos Oficiais para Análise de Substratos para Plantas e Condicionadores de Solo. Brasília, 2008.

MINISTÉRIO DA AGRICULTURA, PECUÁRIA E ABASTECIMENTO (MAPA). Instrução Normativa SDA N. 17. Diário Oficial da União- Seção 1, n.․9, 24 de maio de 2007. Métodos Analíticos Oficiais para Análise de Substratos para Plantas e Condicionadores de Solo. Brasília, 2007.

MINISTÉRIO DA AGRICULTURA, PECUÁRIA E ABASTECIMENTO (MAPA), Instrução Normativa SARC N. 14. Diário Oficial da União- Seção 1, n.ำ 242, 17 de dezembro de 2004. Definições e normas sobre as especificações e as garantias, as tolerâncias, o registro, a embalagem e a rotulagem dos substratos para plantas. Brasília, 2004.

MIYAZAWA, M.; PAVAN, M. A.; BLOCK, M. F. M. Spectrophotometry determination ofnitrate in soil extracts without chemical reduction. Pesquisa Agropecuária Brasileira, 20,129- 133, 1985. 
OLIVEIRA, E. A. G.; RIBEIRO, R. L. D.; GUERRA, J. G. M.; LEAL, M. A. A.; ESPÍNDOLA, J. A. A.; ARAÚJO, E. S. Substrato produzido a partir de fontes renováveis para a produção orgânica de mudas de hortaliças. Seropédica: Embrapa Agrobiologia, (Boletim técnico).4p. 2011.

OLSEN, K. K. Multiple wavelength ultraviolet determinations of nitrate concentration, method comparisons from the preakness brook monitoring project, October 2005 to October 2006. Water Air Soil Pollution, 187, 195-202, 2008. DOI: https://doi.org/10.1007/s11270-007-9508-8.

SEDIYAMA, M. A. N.; SANTOS, I. C.; LIMA, P. C. Cultivo de hortaliças no sistema orgânico. Revista Ceres, Viçosa, v. 61, Suplemento, p. 829-837, 2014. DOI: http://dx.doi.org/10.1590/0034-737x201461000008.

SOUZA, J. L.; RESENDE, P. Manual de horticultura orgânica. Viçosa: UFV. 2006. $673 p$.

TOLEDO, F. H. S. F.; VENTURIN, N.; MACEDO, R. L. G; DIAS, B. A. S; SILVA, I. M. M; NEVES, Y. Y. B; NASCIMENTO, G. O.; CARLOS, L. Influência da qualidade química do substrato no teor de nutrientes em folhas de mudas de eucalipto. Ecologia e Nutrição Florestal, Santa Maria-RS, v.1, n.2, p.89-96, 2013. DOI: http://dx.doi.org/10.13086/2316-980x.v01n02a05.

TRANI, P. E.; FELTRIN, D. M.; POTT, C. A.; SCHWINGEL, M. Avaliação de substratos para produção de mudas de alface. Horticultura Brasileira, 25: 256-260, 2007.

TRANI, P. E.; NOVO, M. C. S. S.; CAVALLARO JÚNIOR, M. L.; TELLES, L. M. G. Produção de mudas de alface em bandejas e substratos comerciais. Horticultura Brasileira, Brasília, v.22, n.2, p.290-294, 2004. 